\title{
Antiinflammatory Activity of Wheat Grass Fortified with Cow Urine Distillate
}

\author{
K. N. KILLARI ${ }^{*}$, K. PRASAD, M. R. TALLURI ${ }^{1}$, Y. K. BOKAM, S. R. NADIMINTI AND C. S. KOMMAVARI \\ Shri Vishnu College of Pharmaceutical Sciences, Bhimavaram-534 201, ${ }^{1}$ Anacipher Clinical Research Organization, \\ Hyderabad-500 013, India
}

Killari et al.: Antiinflammatory activity of Fortified Triticum aestivum with Cow urine

\begin{abstract}
Cow urine distillate appear to possess bioenhancement capacity that increases effectiveness of medicinal products. So, the current research was aimed to evaluate the antiinflammatory and antioxidant activity of wheat grass powder fortified with cow urine distillate. Antiinflammatory activity was studied using carrageenan-induced paw edema in Wistar rats at 100, 200 and $400 \mathrm{mg} / \mathrm{kg}$ doses of wheat grass powder fortified with cow urine distillate and the antioxidant capacity was studied using the ferric thiocyanate method. Wheat grass powder fortified with cow urine distillate showed significant reduction (61.09\%) in peroxide production in the ferric thiocyanate method. All the three doses tested produced significant inhibition of rat paw edema in the carrageenan assay but the $400 \mathrm{mg} / \mathrm{kg}$ dose produced maximum inhibition of rat paw edema $(\mathbf{4 0 . 0 6} \%)$ at the $5 \mathrm{~h}$ time point compared to the control. It is possible to conclude from the results of the study that fortification of wheat grass powder with cow urine distillate enhanced the antioxidant and antiinflammatory activities and further research is necessary to understand the mechanism and phytochemicals responsible for the fortification of the activity of wheat grass.
\end{abstract}

Key words: Triticum aestivum, wheat grass powder, cow urine distillate, antioxidant, antiinflammatory

Oxidative stress (OS) and inflammation are the major risk factors in the pathogenesis of various chronic diseases and the stress is mainly due to the imbalance between the free radicals and antioxidants in the body $^{[1,2]}$. Free radicals are extremely unstable and highly reactive molecules because of their negative state and generally take electrons from other molecules, thus starting a dangerous chain reaction termed as free radical damage ${ }^{[3-5]}$. The free radicals damage the structural integrity of cell membranes, cause changes in the structures of proteins, deoxyribonucleic acid (DNA), ribonucleic acid by withdrawing electrons through oxidation ${ }^{[6]}$ that lead to alterations in normal cellular functions and accelerate cell damage progressing to cell death ${ }^{[7-9]}$. Reactive oxygen species (ROS) are widely believed to be involved in the aetiology of many diseases including inflammation ${ }^{[10]}$. Inflammation is a physiological response of the body to injuries or infections ${ }^{[11,12]}$. There are different types of inflammation in the body, which are mainly acute and chronic inflammations ${ }^{[13]}$ and play an important role in immune system response against injuries and infection by signalling immune cells $\mathrm{s}^{[14]}$ that include macrophages, neutrophils either directly or through inflammatory

*Address for correspondence

E-mail: kishorenaidu.killari@gmail.com

May-June 2019 cytokine production during inflammation. In addition, there are many reports on chronic inflammation to play a significant role in the pathogenesis of age-related diseases like diabetes, cardiovascular and autoimmune diseases $^{[10,15,16]}$.

OS mainly causes imbalance between production of ROS and their elimination by antioxidants in the body and as per the earlier reports, chronic inflammatory diseases are habitually associated with OS. This type of inflammation primarily characterized with no pain but active inflammation with tissue destruction ${ }^{[17]}$. The OS and inflammatory diseases are one of the major reasons for the mortality around the world in recent decades ${ }^{[18,19]}$. So, there is a need to identify the new antiinflammatory and antioxidant drugs to get rid of acute and chronic inflammatory diseases and their side effects $^{[20,21]}$.

This is an open access article distributed under the terms of the Creative Commons Attribution-NonCommercial-ShareAlike 3.0 License, which allows others to remix, tweak, and build upon the work non-commercially, as long as the author is credited and the new creations are licensed under the identical terms

Accepted 25 April 2019

Revised 28 December 2018

Received 19 October 2018

Indian J Pharm Sci 2019;81(3):521-526 
Wheat has been a food crop for mankind since the beginning of agriculture. It is more widely cultivated than any other crop, and world trade is of greater monetary value than all other cereals combined ${ }^{[1]}$. Wheat grass (Triticum aestivum) belongs to the family Poaceae and is commonly called as bread wheat. Wheat grass has been traditionally used as food since ancient times and as well as to treat various diseases and disorders ${ }^{[22-24]}$. Earlier reports on nutritional value and medicinal uses of $T$. aestivum provided that, wheat grass has a significant role in the treatment of various disorders such as OS, some cancers, eczema, ulcers, gastritis, anaemia, asthma, obesity, high blood pressure and diabetes ${ }^{[1,25]}$. Cow urine has an irreplaceable role as an Ayurvedic medicine and has been well described in Sushrita Samhita and Ashtanga Sangraha to be the most effective substance with immeasurable therapeutic values ${ }^{[26]}$. Recent studies reported that the cow urine is a significant bioenhancer ${ }^{[26]}$. There are no previous studies on the evaluation of antiinflammatory activity of wheat grass powder fortified with cow urine distillate. As earlier reports stated that wheat grass powder is of high medicinal values ${ }^{[27]}$ and based on the nutritional values, effective activity of wheat grass powder against $\mathrm{OS}^{[28,29]}$, the present study was carried out to assess in vitro antioxidant and in vivo antiinflammatory activity of orally administered aqueous leaf extract of T. aestivum using carrageenaninduced inflammation in rats.

\section{MATERIALS AND METHODS}

All chemicals used in the current study were of analytical grade. Linolenic acid, ammonium thiocyanate, ferrous chloride, butylated hydroxy toluene (BHT), indomethacin, sodium carboxymethyl cellulose (Na CMC) and carrageenan were purchased from Sigma Chemicals, Mumbai.

Dried T. aestivum (100 g) was directly purchased from the local market (Bhimavaram). The plant material was crushed thoroughly in a mortar and pestle, the powder was completely exhausted by adding small quantities of double-distilled water, which was filtered off every time in a successive manner, and allow drying to yield a dried extract. The dried extract was stored in a desiccator until further usage.

\section{Preparation of wheat grass fortified with a cow urine distillate:}

The obtained dried extract was mixed with cow urine distillate (obtained from ISKCON temple, Bhimavaram)
3-4 times. This process leads to bioenhancing property to the wheat grass powder.

\section{Phytochemical screening:}

Different extracts collected were tested for the presence or absence of different bio active compounds and the total phenolic and alkaloid contents in these extracts were estimated using standard test procedures ${ }^{[30-33]}$.

\section{Antioxidant activity:}

Ferric thiocyanate (FTC) method was used to evaluate the antioxidant activity ${ }^{[34-36]}$ using BHT as a standard against wheat grass extract (WGE) and wheat grass extract fortified with cow urine extract (WGFE). In this method, the extract and the standard were suspended in $4 \mathrm{ml}$ ethanol, mixed with $4.1 \mathrm{ml}$ of $2.52 \%$ linolenic acid in ethanol, $8 \mathrm{ml}$ of $0.02 \mathrm{M}$ phosphate buffer $(\mathrm{pH} 7.0)$ and $3.9 \mathrm{ml}$ of distilled water. The mixture was placed at $40^{\circ}$ and then $0.1 \mathrm{ml}$ was mixed with $9.7 \mathrm{ml}$ of $75 \%$ (v/v) ethanol and $0.1 \mathrm{ml} 30 \%$ ammonium thiocyanate. Three minutes after adding ferrous chloride $(0.1 \mathrm{ml}$ of $2 \times 10^{-2} \mathrm{M}$ ferrous chloride in $3.5 \%$ hydrochloric acid), the absorbance was measured at $500 \mathrm{~nm}$ in a spectrophotometer. This step was repeated every $24 \mathrm{~h}$ until the control (ethanol, the mixture without added sample) reached its maximal absorbance value. Percent inhibition of lipid peroxidation was estimated by the following formula, $\%$ inhibition $=100-\left(\left(\mathrm{A}_{1} / \mathrm{A}_{0}\right) \times 100\right)$, where, $A_{0}$ is the absorbance of the control and $A_{1}$ is the absorbance of the sample extracts/standard.

\section{Experimental animals:}

Healthy adult Wistar rats and mice (National Institute of Nutrition, Hyderabad, India) weighing 220-250 and 25-30 g, respectively were used in the study. The animals were maintained under standard laboratory conditions and were fed regularly with normal pellet diet (Mahavir enterprises Pvt Ltd.; Hyderabad, India). The use and care of the animals in the experimental protocol has been approved by the Institutional Animal Ethics Committee, Shri Vishnu College of Pharmacy (Regd. No. 439/PO/01/a/CPCSEA) following the guidelines of the Committee for the Purpose of Control and Supervision of Experiments on Animals (CPCSEA), Government of India.

\section{Acute toxicity studies:}

Acute toxicity studies were carried out on mice of single sex $(n=6)$ with WGE and WGFE according to 37, Organisation for Economic Co-operation and Development guidelines ${ }^{[37]}$. The maintained animals 
were divided into two groups and were treated with $2000 \mathrm{mg} / \mathrm{kg}$ of both extracts orally. The treated animals were kept aside to observe physical, psychological behaviours and mortality.

\section{Acute inflammation model, carrageenan-induced rat paw edema:}

Eight groups of rats were treated orally with $1 \% \mathrm{Na}$ $\mathrm{CMC}, 5 \mathrm{mg} / \mathrm{kg}$ indomethacin, 100, 200 and $400 \mathrm{mg} / \mathrm{kg}$ of aqueous extracts of WGE and WGFE, respectively and allowed to acclimatize for $60 \mathrm{~min}$ before any injection $^{[38-40]}$. Sixty minutes later, an injection of $1 \%$ carrageenan in normal saline was made into the subplantar region of the right hind paw of each rat in each group. Before induction of edema, the dorsiventral thickness of both paws of each rat was measured using Zeitlin apparatus ${ }^{[38-40]}$. The apparatus consisted of a graduated micrometer, combined with a constant loaded lever system to magnify small changes in the paw thickness during the course of the experiment. The measurements were taken at $1 \mathrm{~h}$ intervals after induction of edema for up to $6 \mathrm{~h}$. Edema was monitored and expressed as percent increase in paw thickness in the carrageenan-injected paw. To assess the edema in control paw (right) saline was injected subcutaneously. Percent inhibition of paw thickness was calculated using the Eqns., \% increase in paw edema $=\mathrm{Y}_{\mathrm{t}}-\mathrm{Y}_{0} \times 100 /$ $\mathrm{Y}_{0}$, where, $\mathrm{Y}_{\mathrm{t}}$ is paw thickness at time $(1,2,3,4,5$ and $6 \mathrm{~h})$ after carrageenan injection, $\mathrm{Y}_{0}$ is paw thickness at $0 \mathrm{~h}$ (before injection). $\%$ inhibition $=100[1-(\mathrm{Yt} / \mathrm{Yc})]$, where, Yt is an average increase in paw thickness in groups tested with test compounds and $\mathrm{Yc}$ is an average increase in paw thickness in control.

\section{Statistical analysis:}

Data of paw thickness were analysed using one-way ANOVA followed by the post hoc Dunnett's test using GraphPad Prism-5 software. The results were expressed as mean \pm SEM. $\mathrm{P}<0.05$ was considered as significant.

\section{RESULTS AND DISCUSSION}

Phytochemical screening of WGE and WGFE showed presence of different phytochemical compounds. There was no great differences observed between them but the intensity of the positive results was high in WGFE compared to WGE. Both the extracts have shown presence of steroids, terpenoids, carbohydrates, phenols, alkaloids, glycosides, oils and amino acids but have shown absence of flavonoids, tannins, saponins and quinones (Table 1). Preliminary phytochemical analysis confirmed the presence of phenols and alkaloids in both WGFE and WGE, which were quantified. WGFE possessed greater phenolic and alkaloid content, $12.58 \pm 42,8.63 \pm .67$ compared to WGE, which had $8.54 \pm 0.33$ and $5.78 \pm 1.36$, respectively

The antioxidant activity results obtained with WGFE and WGE in FTC method confirmed that both extracts possessed antioxidant activity against different free radicals. Both extracts inhibited the free radical (oxidants) formation and linolenic acid peroxidation over 7 days in the FTC method (Table 2 and fig. 1). The antioxidant capacity of both extracts was comparable to that exhibited by the standard BHT and percent inhibition of linolenic acid peroxidation during the study was increased and greater inhibition on d 5 was observed for WGFE and on d 4 for WGE. Percent inhibition produced by WGE was 50.88 on $\mathrm{d} 4$ while for WGFE was 61.20 on day 5.

The toxicity of the extracts WGFE and WGE was evaluated on mice and the extracts were found to be safe up to $2000 \mathrm{mg} / \mathrm{kg}$, the highest dose tested. There was no mortality and physiological changes observed in groups of animals treated with WGFE and WGE.

The antiinflammatory activity possessed by the extracts WGFE and WGE was evaluated in the carrageenaninduced rat paw edema model at 100,200 and $400 \mathrm{mg} / \mathrm{kg}$ doses. Indomethacin, WGFE and WGE treatments produced significant $(\mathrm{p}<0.05)$ reduction in rat paw edema. As the concentration of extracts WGFE and WGE was increased, percent reduction of edema was also increased but both extracts produced lower activity compared to indomethacin, the standard.

TABLE 1: PHYTOCHEMICAL ANALYSIS OF WGE AND WGFE

\begin{tabular}{lcc}
\hline \multirow{2}{*}{ Phytochemicals } & \multicolumn{2}{c}{ Extract } \\
\cline { 2 - 3 } Phytosterols & WGE & WGFE \\
Terpenoids & + & + \\
Glycosides & + & + \\
Saponins & + & + \\
Flavonoids & - & - \\
Tannins & - & - \\
Carbohydrates & - & - \\
Alkaloids & + & + \\
Amino acids & + & + \\
Oils & + & + \\
Quinones & + & + \\
Phenols & - & - \\
\hline WGE is Wheat grass extract. WGFE is wheat grass extract fortified
\end{tabular}

WGE is wheat grass extract. WGFE is wheat grass extract fortified with cow urine 
TABLE 2: ANTIOXIDANT ACTIVITY OF WGE AND WGFE IN FTC METHOD

\begin{tabular}{cccccccc}
\hline Extract/ & \multicolumn{7}{c}{ Percent inhibition } \\
\cline { 2 - 8 } compound & Day 1 & Day 2 & Day 3 & Day 4 & Day 5 & Day 6 & Day 7 \\
\hline WGE & $26.08 \pm 0.55$ & $41.25 \pm 1.23$ & $48.3 \pm 0.35$ & $50.88 \pm 1.17$ & $44.65 \pm 0.52$ & $44.66 \pm 0.32$ & $33.37 \pm 1.11$ \\
WGFE & $45.64 \pm 0.65$ & $52.87 \pm 0.55$ & $59.64 \pm 1.03$ & $59.59 \pm 0.63$ & $61.20 \pm 0.44$ & $55.86 \pm 0.31$ & $50.0 \pm 0.21$ \\
BHT & $84.96 \pm 0.36$ & $86.99 \pm 0.18$ & $84.58 \pm 0.22$ & $82.39 \pm 0.19$ & $82.89 \pm 0.27$ & $85.35 \pm 0.08$ & $84.88 \pm 0.05$ \\
\hline
\end{tabular}

WGE is wheat grass extract. WGFE is wheat grass extract fortified with cow urine, BHT is butylated hydroxytoluene

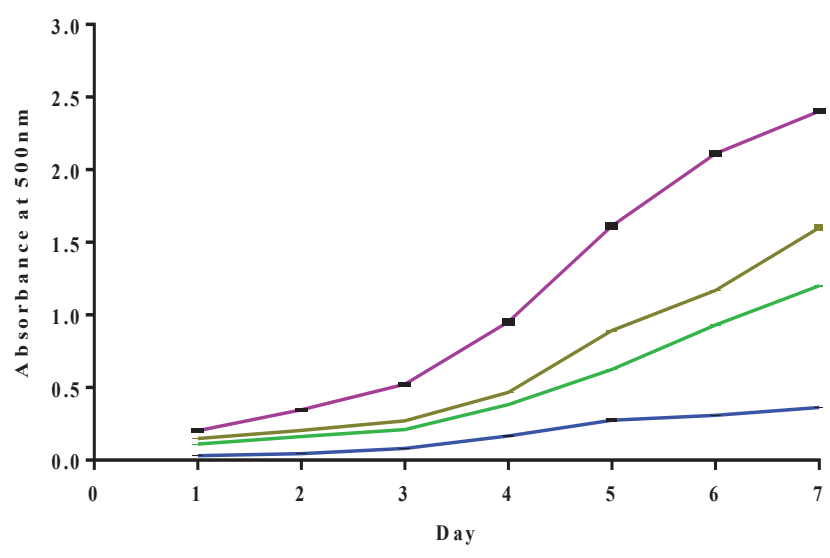

Fig. 1: Absorbance of WGE and WGFE in FTC method Absorbance showed by wheat grass extract (WGE) and wheat grass extract fortified cow urine (WGFE) in FTC method, (-) control, (-) standard, (-) WGE and (-) WGFE

Paw inflammation increased after $1 \mathrm{~h}$ of carrageenan injection and continued to increase up to $4 \mathrm{~h}$ after which the inflammation slowly reduced (fig. 2). The extent of paw inflammation was less in groups treated with high dose of WGFE and WGE and the results obtained confirmed that both extracts exhibited concentration-dependent antiinflammatory activity. WGFE appeared to produce greater activity when compared to WGE group but both extracts were less active than indomethacin.

Fig. 2 revealed that the rat paw edema increased with time after carrageenan injection up to $6 \mathrm{~h}$ with the peak edema volume occurring at $4 \mathrm{~h}$ after injection. Treatment with different doses of WGE, WGFE and the standard drug indomethacin produced dose-dependent inhibition of the edema. Fig. 3 depicts the maximal percent inhibition in rat paw volume produced by each dose of the extract and the standard indomethacin at $6 \mathrm{~h}$ after carrageenan injection. It was observed that maximum inhibition of rat paw edema was produced by indomethacin followed by the $400 \mathrm{mg} / \mathrm{kg}$ dose of WGFE, while $400 \mathrm{mg} / \mathrm{kg}$ dose of WGE produced much lower inhibition. These data demonstrated that the antiinflammatory effect of the WGE was increased by fortification with cow urine, but the effect is still lower than that produce by indomethacin.

The T. aestivum and cow urine have their individual

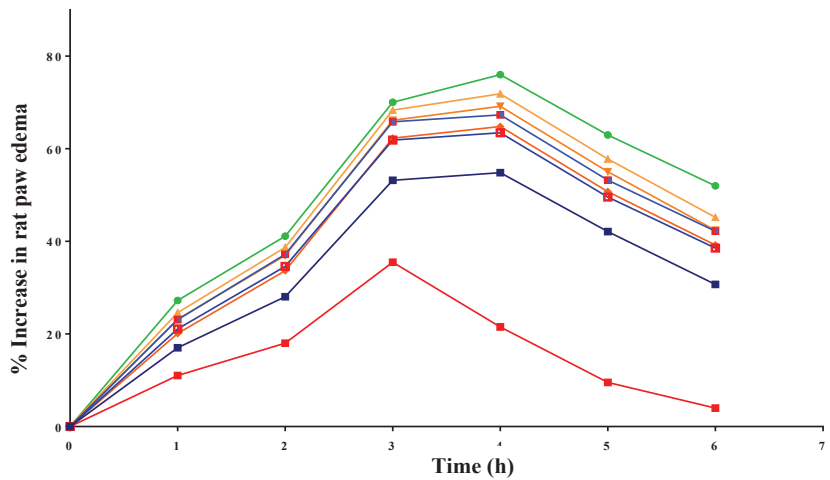

Fig. 2: Changes in rat paw edema after carrageenan injection for $6 \mathrm{~h}$

$(-\bullet-)$ Vehicle, (-n-) indomethacin, $(-\Delta-)$ WGE $100 \mathrm{mg} /$ $\mathrm{kg},(-\nabla-)$ WGE $200 \mathrm{mg} / \mathrm{kg}$, (一४) WGE $400 \mathrm{mg} / \mathrm{kg}$, (一+一) WGFE $100 \mathrm{mg} / \mathrm{kg}$, (一+) WGFE $200 \mathrm{mg} / \mathrm{kg}$, (一匹) WGFE $400 \mathrm{mg} / \mathrm{kg}$. WGE is wheat grass extract. WGFE is wheat grass extract fortified with cow urine

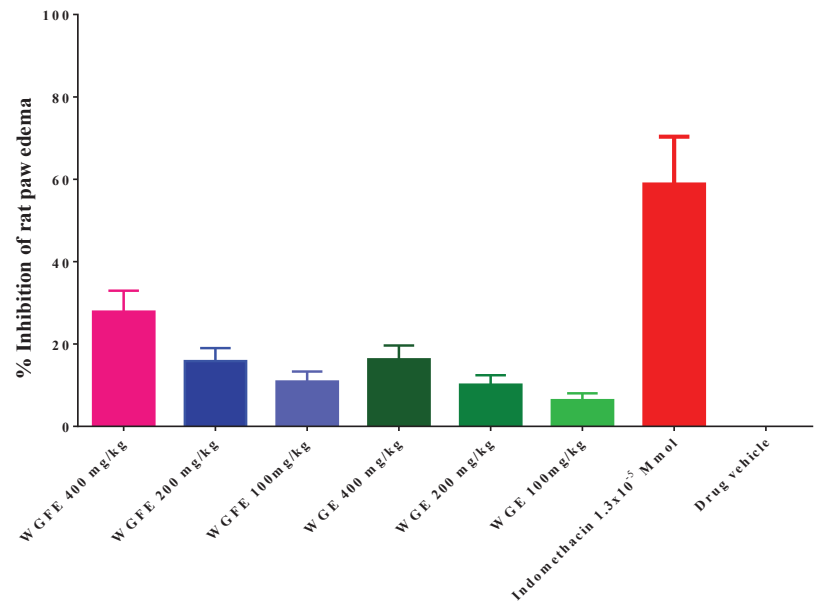

Fig. 3: Inhibition of rat paw edema at different concentrations of WGE, WGFE and indomethacin

WGE is wheat grass extract. WGFE is wheat grass extract fortified with cow urine

medicinal values and both are used as traditional medicine as antiinflammatory drugs ${ }^{[23,41,42]}$. The result of the present study supported their traditional use and provided evidence for antioxidant and antiinflammatory activities.

The carrageenan-induced paw edema method was predominantly used to evaluate the antiinflammatory activity of various test compounds including natural extracts $^{[43]}$. As mentioned above, inflammation is one 
of the major debilitating disease around the world and it involved different mechanisms. In this process, inflammation mainly causes OS. OS is mainly over production of ROS, leading to damage of biomolecules in the body such as lipid, protein, amino acids, and DNA and alteration in cells' normal function ${ }^{[4,13]}$. Hence in the current study FTC method was used to evaluate the antioxidant activity of WGE and WGFE and results demonstrated antiinflammatory activity. Previous studies from our laboratory reported that fortified wheat grass extract possessed free radical scavenging activity against free radicals like superoxide, hydroxyl and $\mathrm{DPPH}^{[45]}$.

Development of edema in the rat paw injected with carrageenan could be due to release of histamine, serotonin, and prostaglandins as previously reported ${ }^{[46]}$. Acute hind paw edema is induced in rats by injecting $0.1 \mathrm{ml}$ of $1 \% \mathrm{v} / \mathrm{v}$ carrageenan, which reached a peak level 3-5 h after carrageenan injection. Prostaglandin E2, a powerful vasodilator, along with other inflammatory vasodilators such as histamine and bradykinin was reported to contribute to the redness and increased blood flow in the areas of acute inflammation ${ }^{[47]}$. All these mediators indirectly activate the formation of free radicals and those free radicals causes the lipid oxidation $^{[48]}$.

The results of the present investigation revealed the antioxidant and antiinflammatory activities possessed by the WGFE and WGE and also that fortification with cow urine might increases these biological activities. The current research work demonstrated that the $T$. aestivum extract and $T$. aestivum extract fortified with cow urine, both exhibited significant antioxidant and antiinflammatory activities. The fortified extract showed higher contents on phytochemical analysis and better biological activity. Hence the current approach to fortify natural extracts with cow urine to obtain better activity appeared to be working. Further research must focus on isolation and identification of compounds responsible for the enhancement of activity when the extract was fortified with cow urine.

\section{Acknowledgements:}

The authors thank the authorities of AU College of Pharmaceutical Sciences, Andhra University and Shri Vishnu College of Pharmacy for providing the necessary facilities to complete the current research work.

\section{Conflicts of interest:}

The authors declare that there is no conflict of interest.

\section{Financial support and sponsorship:}

Nil.

\section{REFERENCES}

1. Runjala S, Murthy YLN. Product Development with Wheat Grass and Nutrient Analysis. Int J Sci Res 2016;5(10):633-45.

2. Danesh J, Kaptoge S, Mann AG, Sarwar N, Wood A, Angleman $\mathrm{SB}$, et al. Long-term interleukin-6 levels and subsequent risk of coronary heart disease: two new prospective studies and a systematic review. PLoS Med 2008;5:e78.

3. Cheeseman KH, Slater TF. An introduction to free radicals chemistry. Br Med Bull 1993;49:481-93.

4. Hussain SP, Hofseth LJ, Harris CC. Radical causes of cancer. Nat Rev Cancer 2003;3(4):276-85.

5. Federico A, Morgillo F, Tuccillo C, Ciardiello F, Loguercio C. Chronic inflammation and oxidative stress in human carcinogenesis. Int J Cancer 2007;121(11):2381-6.

6. Mohammed AA, Ibrahim AA. Pathological roles of reactive oxygen species and their defence mechanism. Saudi Pharm J 2004;12:1-18.

7. McCord JM. The evolution of free radicals and oxidative stress. Am J Med 2000;108:652-9.

8. Pisoschi AM, Pop A. The role of antioxidants in the chemistry of oxidative stress: a review. Eur J Med Chem 2015;97:55-74.

9. Khanna RD, Karki K, Pande D, Negi R, Khanna RS. Inflammation, Free Radical Damage, Oxidative Stress and Cancer. Microinflammation 2014;1:109.

10. Khansari N, Shakiba Y, Mahmoudi M. Chronic Inflammation and Oxidative Stress as a Major Cause of Age- Related Diseases and Cancer. Recent Pat Inflamm Allergy Drug Discov 2009;3:73-80.

11. Gill R, Tsung A, Billiar T. Linking oxidative stress to inflammation: Toll-like receptors. Free Radic Biol Med 2010;48:1121-32.

12. Waris G, Ahsan H. Reactive oxygen species: role in the development of cancer and various chronic conditions. J Carcinog 2006;5:14.

13. Arias JI, Aller MA, Arias J. Surgical inflammation: a pathophysiological rainbow. J Transl Med 2009;7:19.

14. Bochsler PN, Slauson DO. Inflammation and repair of tissue. In: Slauson DO, Cooper BJ, editors. Mechanisms of Disease: A Textbook of Comparative General Pathology. 3rd ed. MO, St. Louis: Elsevier; 2002. p. 141-245.

15. Pearce RK, Owen A, Daniel S, Jenner P, Marsden CD. Alterations in the distribution of glutathione in the substantia nigra in Parkinson's disease. J Neural Transm 1997;104(67):661-77.

16. Smith CD, Carney JM, Starke-Reed PE, Oliver CN, Stadtman ER, Floyd RA, et al. Excess brain protein oxidation and enzyme dysfunction in normal aging and in Alzheimer disease. Proc Natl Acad Sci U S A 1991;88(23):10540-3.

17. Chapple IL. Reactive oxygen species and antioxidants in inflammatory diseases. J Clin Periodontol 1997;24(5):287-96.

18. McCarberg B, Gibofsky A. Need to develop new nonsteroidal anti-inflammatory drug formulations. Clin Ther 2012;34(9):1954-63. 
19. Reyes-Gordillo K, Shah R, Muriel P. Oxidative Stress and Inflammation in Hepatic Diseases: Current and Future Therapy. Oxid Med Cell Longev 2017;2017:3140673.

20. Morrison C, Beauchamp T, MacDonald H, Beattie M. Implementing a non-steroidal anti-inflammatory drugs communication bundle in remote and rural pharmacies and dispensing practices. BMJ Open Qual 2018;7(3):e000303.

21. Fokunang CN, Fokunang ET, Frederick K. Overview of non-steroidal anti-inflammatory drugs (NSAIDs) in resource limited countries. MOJ Toxicol 2018;4(1):5-13.

22. Wigmore A. The wheat grass book. New York, New York, United States: Penguin Random House LLC.; 1985.

23. Ikram M. Economic potential of medicinal plants. Hamdard Med 1983;26:16-7.

24. Laurent D, Costa R, Modesto J, Kohler F, Le Bars P, Pellegrin F. Fumonisin: a major problem in New-Caledonia. Rev Med Vet 1998;149:702.

25. Bar-Sela G, Cohen M, Ben-Arye E, Epelbaum R. The Medical Use of Wheatgrass: Review of the Gap Between Basic and Clinical Applications. Mini Rev Med Chem 2015;15:1002-10.

26. Randhawa GK. Cow urine distillate as bioenhancer. J Ayurveda Integr Med 2010;1(4):240-41.

27. Khan A, Srivastava V. Antitoxic and Bioenhancing role of Kamdhenu ark2 (cow urine distillate) on fertility rate of male mice (Mus musculus) affected by cadmium chloride Toxicity. Int J Cow Sci 2005;1:43-46.

28. Pham-Huy LA, He H, Pham-Huy C. Free radicals, antioxidants in disease and health. Int J Biomed Sci 2008;4(2):89-96.

29. Kulkarni SD, Tilak JC, Acharya R, Rajurkar NS, Devasagayam TP, Reddy AV. Evaluation of the Antioxidant Activity of Wheatgrass (Triticum aestivum L.) as a Function of Growth under Different Conditions. Phytother Res 2006;20:218-27.

30. Tiwari P, Kumar B, Kaur M, Kaur G, Kaur H. Phytochemical screening and extraction: Areview. Int Pharm Sci 2011;1(1):98106.

31. Evans WC. Trease and Evans Pharmacognosy. 15th ed. London: W.B. Saunders Company Ltd.; 2002. p. 23-67.

32. Singleton VL, Rossi JA. Colorimetry of total phenolics with phosphomolybdic acid phosphotungstic acid reagents. Am J Enol Vitic 1965;16:144-58.

33. Fazel S, Hamidreza $M$, Rouhollah $G$, Verdianrizi $M$. Spectrophotometric determination of total alkaloids in some Iranian medicinal plants. Thai J Pharm Sci 2008;32:17-20.

34. Gulçin Y, Elias R, Gepdiremen A, Boyer L, Koksal E. A comparative study on the antioxidant activity of fringe tree (Chionanthus virginicus L.) extracts. Afr J Biotechnol 2007;6:410-8.

35. Elmastas M, Isildak O, Turkekul I, Temur N. Determination of antioxidant activity and antioxidant compounds in wild edible mushrooms. J Food Compos Anal 2007;20:337-45.

36. Saha K, Lajis NH, Israf DA, Hamzah AS, Khozirah S, Khamis $\mathrm{S}$, et al. Evaluation of antioxidant and nitric oxide inhibitory activities of selected Malaysian medicinal plants. J Ethnopharmacol 2004;92(2-3):263-7.

37. Organisation for Economic Co-operation and Development (OECD). Acute Oral Toxicity-Fixed Dose. 2001. Available from: https://www.oecd-ilibrary.org/environment/test-no-420acute-oral-toxicity-fixed-dose-procedure_9789264070943en.

38. Winter CA, Risely EA, Nuss GW. Carrageenan-induced edema in hind paw of the rats as an assay for anti-inflammatory drugs. Proc Soc Exp Biol Med 1962;111:544-7.

39. Battu GR, Zeitlin IJ, Gray AI. Anti-inflammatory activity of adjuvant-induced arthritis in rats of octanordammarane triterpenes from resin extracts of Commiphora Kua. Br J Pharmacol 2000;133:199.

40. Mallikarjuna Rao T, Ganga Rao B, Venkateswara Rao Y. Anti-Inflammatory Activity of Chrozophora rottleri Extracts on Carrageenan-Induced Rat Paw Edema. Int J Pharmacol Phytochem Ethnomed 2016;3:20-26.

41. Jain NK, Gupta VB, Garg R, Silawat N. Efficacy of cow urine therapy on various cancer patients in Mandsaur District, India -A survey. Int J Green Pharm 2010;4:29-35.

42. The wealth of India, Council of Scientific \& Industrial research, New Delhi. Available from: https://www.niscair.res. in/activitiesandservices/products/wealth-of-indiaFolder2010. pdf.

43. Lee YY, Saba E, Irfan M, Kim M, Chan JY, Jeon BS, et al. The anti-inflammatory and anti-nociceptive effects of Korean black ginseng. Phytomedicine 2018;54:169-81.

44. Braca A, Fico G, Morelli I, DeSimone F, Tome F, De Tommasi $\mathrm{N}$. Antioxidant and free radical scavenging activity of flavanol glycosides from different Aconitum species. J Ethnopharmacol 2003;86:63-7.

45. Ashya SK, Kishore NK, Jagadeesh P. In vitro antioxidant activity of Wheat grass powder. J Integral Sci 2018;1(4):7-11.

46. Alluri VK, Chirravuri VR, Tayi VNR, Reddy KN, Trimurtulu $\mathrm{G}$. In vitro and in vivo antioxidant activity of Aphanamixis polystachya Bark. Am J Infect Dis 2009;5:60-7.

47. Mohamed STK, Azeem AK, Dilip C, Sankar C, Prasanth NV, Duraisami R. Anti-inflammatory activity of the leaf extracts of Gendarussa vulgaris Nees. Asian Pac J Trop Biomed 2011;1(2):147-9.

48. Conner EM, Grisham MB. Inflammation, free radicals, and antioxidants. Nutrition 1996;12(4):274-7. 